\title{
KARAKTERISTIK AIR LIMBAH RUMAH TANGGA (grey water) PADA SALAH SATU PERUMAHAN MENENGAH KEATAS YANG BERADA DI TANGERANG SELATAN
}

\section{CHARACTERISTIC OF DOMESTIC WASTE WATER (grey water) IN ONE OF MID LEVEL RESIDENTIAL AREA IN SOUTH TANGERANG}

\author{
Alfrida E. Suoth ${ }^{1}$, Ernawita Nazir ${ }^{1}$ \\ (Diterima tanggal 19-10-2016; Disetujui tanggal 28-11-2016)
}

\begin{abstract}
ABSTRAK
Air limbah rumah tangga atau grey water $(\mathrm{GW})$ adalah air yang berasal dari kegiatan rumah tangga seperti dapur, mandi, cucian, dan bersih rumah/pel namun tidak termasuk yang berasal dari WC (water closet). GW mengandung bahan kimia yang di gunakan dalam aktifitas rumah tangga dan harus diolah agar tidak mencemari dan tidak membahayakan kesehatan dan lingkungan. Sebelum dilakukan pengelolaan, perlu diketahui karakteristik air limbah tersebut, agar tindakan pengelolaannya tepat sasaran. Pada penelitian ini telah dilakukan pengambilan contoh uji air limbah rumah tangga di 10 rumah berada di Perumahan Batan Indah, Kelurahan Kademangan, Kota Tangerang Selatan yang merupakan perumahan kelas menengah ke atas. Parameter yang diuji adalah pH, Suhu, DHL, TSS, BOD, COD, minyak lemak dan deterjen. Hasil pengujian contoh grey water di 10 rumah menunjukkan kisaran nilai untuk parameter pH 6,2 - 8,5; BOD 121 - $151 \mathrm{mg} / \mathrm{L}$; TSS 121-127 mg/L; COD 79 - $700 \mathrm{mg} / \mathrm{L}$ dan minyak lemak 6 - 95 .mg/L. Hasil analisis grey water bila di bandingkan dengan peraturan Kementerian Lingkungan Hidup No 112 Tahun 2003 tentang Baku Mutu Air Limbah Domestik pada beberapa rumah melebihi baku mutu.. Untuk parameter detergen belum diatur dalam baku mutu limbah domestik, selanjutnya di bandingkan dengan as III yang merupakan syarat baku mutu air permukaan.. Konsentrasi detergen berkisar antara 8,8 - 34 mg/L, nilai tersebut 40 - 170 kali lebih tinggi dari yang diperbolehkan di perairan yaitu 0,2 mg/L. Dibutuhkan pengelolaan GW agar tidak semakin mencemari perairan yang ada di sekitarnya.
\end{abstract}

Kata kunci: Air limbah domestik, Grey water, Perumahan menengah keatas, Tangerang Selatan, parameter BOD, COD

\begin{abstract}
Domestic wastewater or greywater $(G W)$ is all wastewater originated from households or office buildings activities such as kitchen sink, bathroom, and laundry exclude the discharge of toilet. The wastewater contain chemicals that must be treated to avoid environment pollution which affects the environmental health. Before the treatment, the characterization of wastewater should be determined in order to attain the proper action. This study was conducted to analyze the characteristics of domestic wastewater in 10 houses in the Batan Indah area, South Tangerang. The tested parameters were $\mathrm{pH}$, temperature, DHL, TSS, BOD, COD, oil \& grease, and detergents. The test results of $13 \mathrm{GW}$ samples from 10 houses showed the range of values for the each parameter are pH: 6.2 to 8.5; BOD : 121-151 mg/L; TSS : 121-127 mg/L; COD : 79-700 mg/L and fatty oils : 6-95 $\mathrm{mg} / \mathrm{L}$. The results of GW analysis were compared to the Environmental Ministry Decree No. 112 of 2003 concerning Domestic Wastewater Quality Standard, and found some exceeded results. The parameter of detergent has not been set in the wastewater domestic quality standards, so it was correlated to the water quality class III of PP 82/2001. Detergent concentration ranged from 8.8 to $34 \mathrm{mg} / \mathrm{L}$, the value was 40-170 times higher than allowed in the waters is $0.2 \mathrm{mg} / \mathrm{L}$. Therefore, GW treatment is required to protect the environment from further pollution.
\end{abstract}

Keywords: Domestic waste water, Grey water, Perumahan menengah keatas, Tangerang Selatan, BOD COD parameter

1) Puslitbang Kualitas dan Laboratorium Lingkungan, KLHK, Serpong, Fungsional Pedal 


\section{PENDAHULUAN}

Masalah air limbah di Indonesia saat ini masih menjadi masalah yang serius. Air limbah bisa berasal buangan rumah tangga, industri maupun tempat- tempat umum lain yang mengandung bahan - bahan yang dapat membahayakan kehidupan manusia maupun makhluk hidup yang dapat mengganggu kelestarian lingkungan. Grey water (GW) adalah air limbah yang berasal dari kegiatan rumah tangga namun tidak termasuk yang berasal dari toilet. Grey water dinilai sebagai air limbah yang kadar pencemarnya ringan (light) dibandingkan dengan air limbah yang berasal dari kegiatan industri (1). Selain GW, rumah tangga juga menghasilkan limbah kotoran manusia, yang dikenal dengan blackwater. Bahan organik, anorganik, maupun gas yang terkandung di dalam limbah cair rumah tangga dapat mencemari lingkungan serta menyebabkan berbagai penyakit. Selain itu, sebagian bahan tersebut diurai oleh mikroorganisme menjadi suatu senyawa yang dapat menimbulkan bau tidak sedap. Air limbah terdiri dari $99.7 \%$ air dan $0.3 \%$ bahan lain, seperti bahan padat, koloid dan terlarut. Bahan lain tersebut terbagi atas bahan organik dan anorganik (2).Beberapa ahli sanitasi menambahkan satu kategori lagi untuk limbah tetesan AC dan kulkas sebagai clearwater. Dalam kehidupan seharihari, clearwater umumnya tidak berjumlah banyak, terutama dari kulkas, sehingga sulit diolah untuk dimanfaatkan kembali. Tetesan AC jumlahnya sedikit lebih banyak dan bila ditampung dalam wadah dapat langsung digunakan untuk keperluan bersih-bersih, misalnya cuci piring atau pakaian.

Umumnya, orang membuang limbah greywater langsung ke selokan yang ada di depan rumah, tanpa diolah terlebih dahulu. Akibatnya, sungai yang menjadi tempat bermuaranya selokan berpotensi tercemar; warnanya menjadi coklat dan mengeluarkan bau busuk. Selain bisa menyebabkan ikan-ikan mati, zatzat polutan yang terkandung di dalam limbah juga bisa menjadi sumber penyakit, seperti kolera, disentri, dan berbagai penyakit lain.

Sejalan dengan pertambahan penduduk maka kebutuhan akan perumahan juga semakin meningkat. Daerah Tangerang Selatan adalah sebuah kota yang baru terbentuk dan berada di bawah pemerintahan provinsi Banten. Kota Tangerang Selatan menjadi salah satu daerah tujuan pengembang memperluas jaringan bisnis perumahannya dikarenakan berada di sekitar Jabodetabek. Perumahan yang semakin banyak memberi dampak juga terhadap kegiatan yang dilakukan dan air limbah rumahtangga yang di hasilkan dari kegiatan tsb. Perumahan Batan Indah yang menjadi lokasi penelitan berada di Kelurahan Kademangan Kota tangerang Selatan. Perumahan Batan Indah adalah perumahan kelas menengah keatas, luas tanah minimal $150 \mathrm{~m}^{2}$ dengan penghuni yang sebagian besar adalah PNS. Dikelompokkan dalam kriteria menengah keatas berdasarkan luas tanah yang minimal $150 \mathrm{~m}^{2}$. Air limbah yang dihasilkan dari perumahan ini dialirkan ke sungai kecil Cirompang yang berlokasi di belakang perumahan, selanjutnya air limbah dialirkan ke sungai Cisadane.

Tujuan dari penelitian ini adalah mengetahui karakteristik dari grey water yang dihasilkan oleh salah satu perumahan menengah keatas yang berada di Tangerang Selatan. Diharapkan setelah di ketahui karakteristik grey water 
di perumahan, dapat dilakukan tindakan pengelolaannya sehingga grey water dapat dioleh dan di gunakan kembali (reuse).

\section{METODOLOGI}

\section{a. Pengambilan Contoh Uji}

Pengambilan contoh uji air limbah rumah tangga/grey water (GW) sesuai SNI. 6989. 59.2008 dengan metode komposit waktu.
Titik sampling dilakukan pada outlet aliran air limbah rumah tangga sebelum masuk ke drainase. Ada 10 rumah sebagai titik sampling yaitu10 rumah yang disampling sekali $(8.6,7.9,7.6,9.9,9.3,9.5,6.3,5.2,4.2$, 2.1) dan 3 rumah yang diambil 2 kali yaitu titik 4.2b, 6.3b, 9.9b Outlet dari 10 rumah merupakan lokasi titik sampling yang dialiri air limbah yang berasal dari kegiatan rumah tangga (GW).

Tabel 1. Daftar parameter, volume sampel, jenis wadah dan pengawet yang digunakan (3)

\begin{tabular}{l|l|l|l}
\hline \multicolumn{1}{c|}{ Parameter } & \multicolumn{1}{|c|}{ Jenis wadah } & \multicolumn{1}{c}{ Volume } & \multicolumn{1}{c}{ Pengawet } \\
\hline Total Suspended Solid, TSS & Polietilen (PE) & $1000 \mathrm{~mL}$ & dinginkan \\
Biochemical Oxygen Demand, BOD $_{5}$ & Polietilen (PE) & $500 \mathrm{~mL}$ & dinginkan \\
Chemical Oxygen Demand, COD & Polietilen (PE) & $250 \mathrm{~mL}$ & $\mathrm{H}_{2} \mathrm{SO}_{4}$ sampai $\mathrm{pH}<2$ \\
Minyak dan Lemak & Glass & $1000 \mathrm{~mL}$ & $\mathrm{H}_{2} \mathrm{SO}_{4}$ sampai $\mathrm{pH}<2$ \\
Detergen, MBAS & Polietilen (PE) & $1000 \mathrm{~mL}$ & dinginkan \\
\hline
\end{tabular}

Parameter pH, temperatur, daya hantar listrik (DHL), total dissolved solid (TDS) diukur langsung di lapangan.

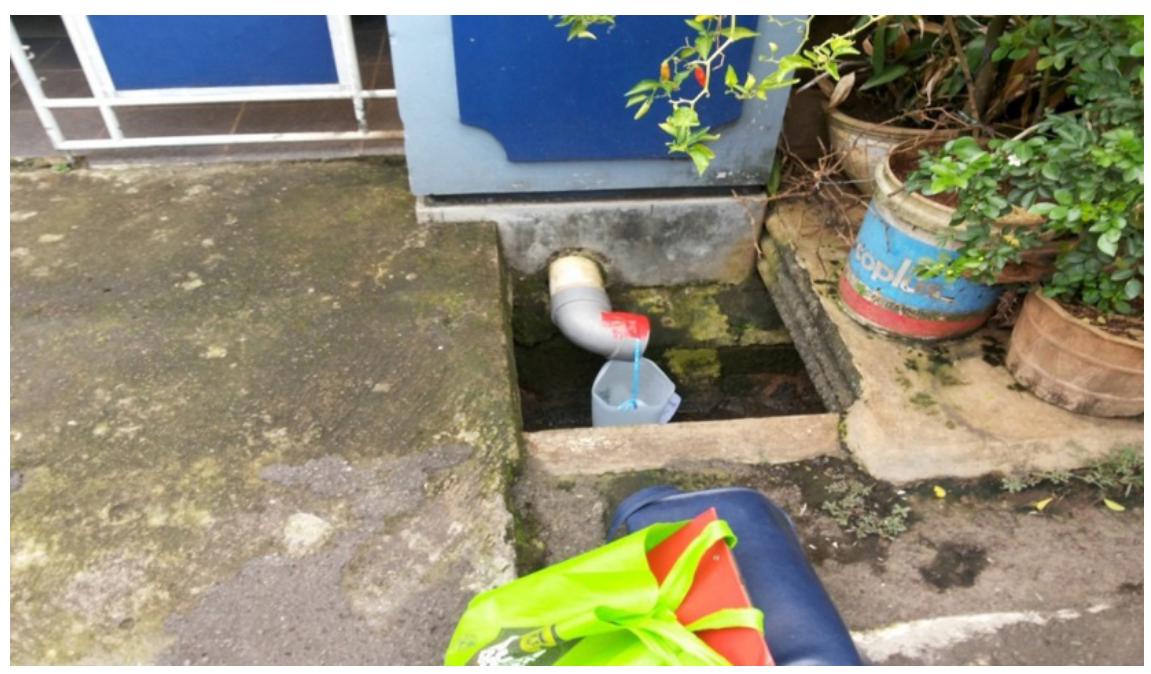

Gambar 3. Foto lokasi sampling grey water di perumahan Batan Indah 
Tabel 3. Acuan Metode Analisis Air Limbah rumah tangga

\begin{tabular}{cc}
\hline Parameter & Metode \\
\hline pH & SNI 06-6989-11-2004 \\
Temperatur, suhu & APHA 2550-2012 \\
DayaHantarListrik, DHL & SNI 06-6989-1-2004 \\
Total padatan terlarut, TDS & SNI 06-6989.27-2005 \\
Biochemical Oxygen Demand, BOD & JIS K 0102.21-2008 \\
Chemical Oxygen Demand, COD & SNI 6989.2-2009 \\
Total Dissolved Solid $($ TDS $)$ & IK.01/A/LPDL (elektrometri) \\
Minyak dan Lemak & SNI 6989.10-2011 \\
Detergen, MBAS & SNI 6989.51-2005
\end{tabular}

\section{b) Analisis Contoh Uji}

Analisis air limbah yang berasal dari kegiatan rumah tangga di lakukan di laboratorium Puslitbang Kualitas dan Laboratorium Lingkungan (P3KLL) sesuai dengan metode yang di sajikan pada Tabel 3

\section{HASIL DAN PEMBAHASAN}

Contoh uji air limbah yang diambil berasal dari kegiatan mandi, cuci, masak/dapur, bersih-bersih rumah (grey water). Saat ini belum ada bakumutu yang mengatur penggunaan maupun batasan konsentrasi yang di perbolehkan untuk grey water. Keputusan Menteri Negara Lingkungan Hidup No. 112 Tahun 2003 tentang Baku Mutu (BM) Air Limbah Domestik yang di sebutkan pada pasal 1 ayat 1 yaitu bahwa air limbah domestik adalah air limbah yang berasal dari usaha dan atau kegiatan pemukiman (real estate), rumah makan (restauran), perkantoran, perniagaan, apartemen dan asrama (4)

Tabel 4. Hasil analisa air air limbah rumah tangga (grey water) di salah satu perumahan menengah yang ada di Tangerang Selatan

\begin{tabular}{c|c|c|c|c|c|c|c|c}
\hline Kode sampel & $\mathrm{pH}$ & Suhu & DHL & TSS & BOD $_{5}$ & COD & TDS & $\begin{array}{c}\text { Minyak } \\
\text { Lemak }\end{array}$ \\
\hline 8.6 & 8,5 & 29 & 222 & 50 & 23 & 84 & 107 & 11 \\
7.9 & 7,1 & 28 & 252 & 121 & 205 & 435 & 123 & 59 \\
7.6 & 6,6 & 31 & 386 & 125 & 238 & 700 & 186 & 66 \\
9.9 & 7,2 & 28 & 152 & 122 & 47 & 103 & 73 & 26 \\
9.3 & 6,9 & 28 & 191 & 127 & 121 & 283 & 91 & 36 \\
9.5 & 6,5 & 27 & 394 & 151 & 161 & 367 & 190 & 47 \\
6.3 & 7,2 & 28 & 307 & 80 & 290 & 529 & 148 & 95 \\
5.2 & 6,3 & 28 & 746 & 43 & 99 & 207 & 363 & 36 \\
4.2 & 6,2 & 28 & 209 & 19 & 129 & 259 & 100 & 19 \\
2.1 & 7,1 & 28 & 160 & 19 & 35 & 79 & 77 & 28 \\
$9.9 \mathrm{~b}$ & 6,4 & 26 & 256 & 99 & 123 & 614 & 122 & 41 \\
$6.3 \mathrm{~b}$ & 6,7 & 26 & 276 & 33 & 66 & 123 & 128 & 15 \\
$4.2 \mathrm{~b}$ & 8,2 & 26 & 549 & 14 & 86 & 167 & 269 & 6 \\
\hline
\end{tabular}




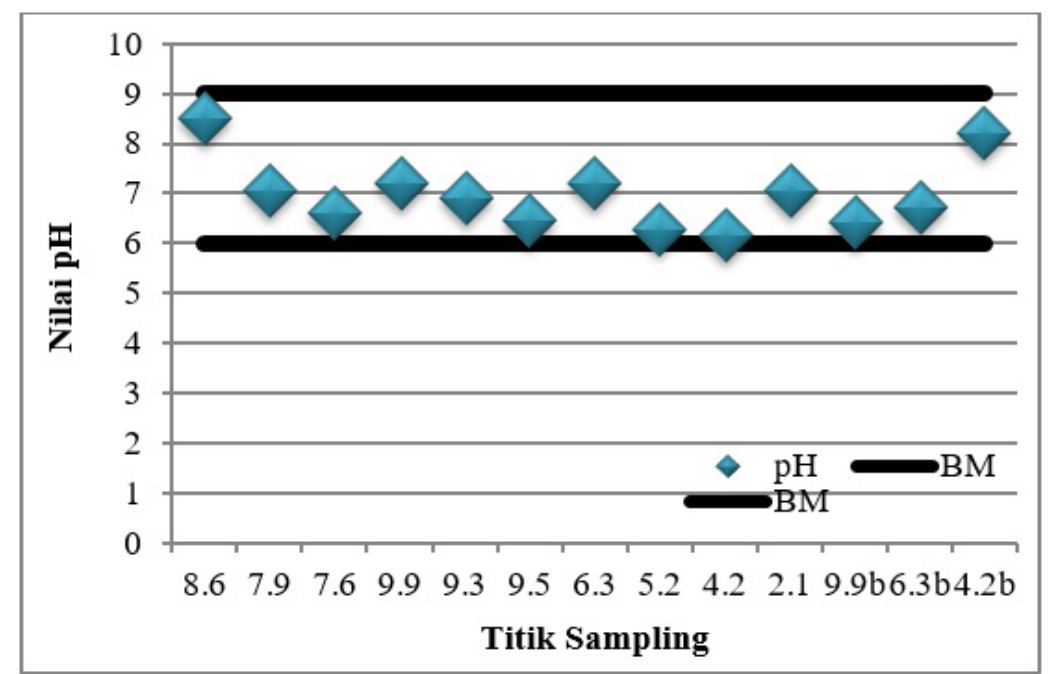

Gambar 4. Grafik pH dalam air limbah

Nilai $\mathrm{pH}$ pada contoh uji yang diambil masih berada pada range BM yang di persyaratkan yaitu 6 - 9. Pada dasarnya $\mathrm{pH}$ juga berkaitan erat dengan karbondioksida dan alkalinitas. Pada $\mathrm{pH}<5$, alkalinitas dapat mencapai 0 . Semakin tinggi $\mathrm{pH}$, semakin tinggi pula nilai alkalinitas dan semakin rendah karbondioksida bebas. Larutan yang bersifat asam ( $\mathrm{pH}$ rendah) bersifat korosif (5). Biota akuatik sensitif terhadap perubahan $\mathrm{pH}$ dan menyukai nilai $\mathrm{pH}$ sekitar 7-8,5. Nilai pH sangat mempengaruhi proses biokimiawi perairan, misalnya proses nitrifikasi akan berakhir jika $\mathrm{pH}$ rendah. Toksisitas logam memperlihatkan peningkatan pada $\mathrm{pH}$ rendah.
Nilai DHL dalam contoh air limbah yang dianalisa berada pada range 152-749 $\mu \mathrm{S} / \mathrm{cm}$. Konduktivitas (Daya Hantar Listrik/DHL) adalah gambaran numeric dari kemampuan air untuk meneruskan aliran listrik. Oleh karena itu, semakin banyak garam-garam terlarut yang dapat terionisasi, semakin tinggi pula nilai DHL. Reaktivitas, bilangan valensi, dan konsentrasi ion-ion terlarut sangat berpengaruh terhadap nilai DHL. Konduktifitas air tergantung dari konsentrasi ion dan suhu air. Oleh karena itu kenaikan padatan terlarut akan mempengaruhi garam-garam terlarut misalnya natrium, magnesium, klorida, sulfat dan lainlain dapat menaikkan Konduktifitas(4). Asam,

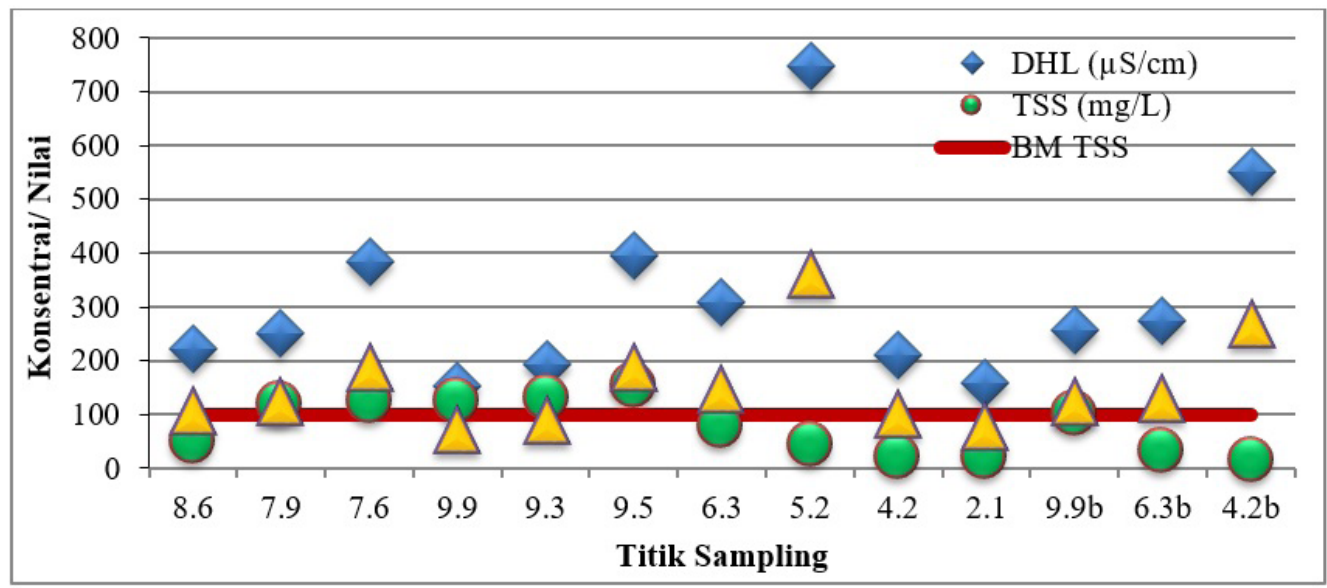

Gambar 5. Grafik DHL, TDS dan TSS dalam air limbah rumah tangga 
basa dan garam merupakan penghantar listrik (konduktor) yang baik, sedangkan bahan organik misalnya sukrosa dan benzena yang tidak dapat mengalami disosiasi, merupakan penghantar listrik yang jelek. Konduktivitas dinyatakan dengan dengan satuan $\mu \mathrm{mhos} / \mathrm{cm}$ atau $\mu$ Siemens $/ \mathrm{cm}$. Perairan alami sekitar $20-1500 \mu \mathrm{mhos} / \mathrm{cm}$ (3). Nilai TDS dapat diperkirakan dengan bilangan 0,55 - 0,75. Nilai TDS biasanya lebih kecil dari pada nilai DHL. Pada penentuan nilai TDS, bahan-bahan yang mudah menguap (volalite) tidak terukur karena melibatkan proses pemanasan.

Konsentrasi TSS pada umumnya di bawah BM kecuali di titik 7.9; 7.6; 9.9; 9.3 dan 9.5. yang nilainya berkisar $121-127 \mathrm{mg} / \mathrm{L}$ lebih tinggi dari BM dipersyaratkan $100 \mathrm{mg} / \mathrm{L}$. Padatan tersuspensi total (total suspened solid atau TSS) adalah bahan-bahan tersuspensi (diameter $>1 \mu \mathrm{m}$ ) yang bertahan pada saringan milipore dengan diameter pori $0,45 \mu \mathrm{m}$. TSS terdiri pada lingkungan berasal dari lumpur dan pasir halus serta jasad-jasad renik,yang terutama disebabkan oleh kikisan tanah atau erosi tanah yang terbawa kebadan air. Dalam limbah rumah tangga TSS yang tinggi bisa berasal dari berbagai aktifitas seperti cuci, mandi dan bersih-bersih rumah. TSS, dapat meningkatkan nilai kekeruhan yang selanjutnya akan menghambat penetrasi cahaya matahari ke kolom air dan akhirnya berpengaruh terhadap proses fotosintesis di perairan.

Padatan terlarut total (Total Dissolved Solid atau TDS) adalah bahan-bahan terlarut (diameter $<10^{-6} \mathrm{~mm}$ ) dan koloid (diameter $10^{-6} \mathrm{~mm}-10^{-3} \mathrm{~mm}$ ) yang berupa senyawasenyawa kimia dan bahan-bahan lain ,yang tidak tersaring pada kertas saring berdiameter $0,45 \mu \mathrm{m}$. TDS bisa berasal dari penggunaan bahan-bahan yang mengandung kation dan anion yang digunakan dalam kegiatan rumah tangga (4).

Konsentrasi minyak dan lemak di semua titik secara umum melebihi BM yang dipersyaratkan (10 mg/L) kecuali di titik 4.2b di temukan 6 $\mathrm{mg} / \mathrm{L}$. Konsentasi minyak dan lemak di titik sampling yang lainnya berkisar $11-95 \mathrm{mg} / \mathrm{L}$. Konsentrasi ini cukup tinggi terutama di beberapa titik, hal ini menunjukkan pemakaian minyak yang tinggi terutama dalam kegiatan yang berasal dari dapur. Minyak dan lemak yang masuk ke perairan dapat menyebar dan membentuk lapisan tipis yang terdapat

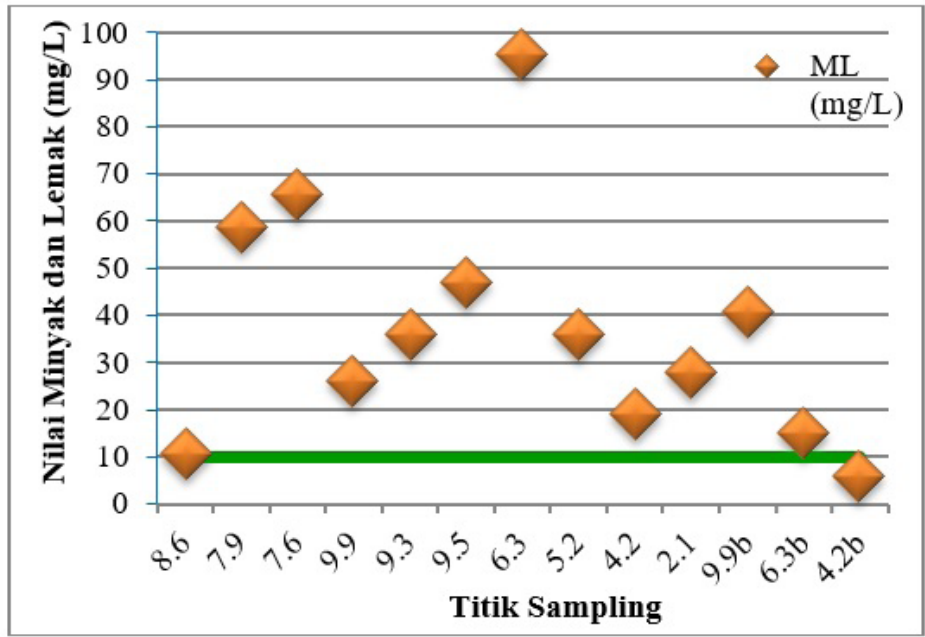

Gambar 6. Grafik konsentrasi minyak dan lemak dalam air limbah 
di permukaan, emulsi dan fraksi terserap. Di perairan interaksi bentuk minyak sangat kompleks di pengaruhi oleh nilai specific grafity, titik didih, tekanan permukaan, viskositas, kelarutan dan penyerapan. Kadar minyak mineral dan produk produk petroleum yang diperkenankan terdapat dalam air minum berkisar antara 0,01-0,1 mgL. Menurut UNESCO/WHO/UNEP 1992, kadar yang melebihi $0,3 \mathrm{mg} / \mathrm{L}$ bersifat toksik terhadap beberapa jenis ikan tawar (5).

Biochemical Oxygen Demand (BOD) menunjukkan jumlah bahan organik yang ada di dalam air yang dapat di degradasi secara biologis. Pada hasil analisa di temukan ada 6 titik dengan nilai BOD diatas BM yaitu dititik 7.9; 7.6; 9.3; 6.3; 4.2 dan 9.9b. Konsentrasi yang melebihi berkisar 121-151 mg/L. Air dengan nilai BOD tinggi menunjukkan jumlah pencemar yang tinggi terutama pencemar yang disebabkan oleh bahan organik.

COD atau Chemical Oxygen Demand, memberikan informasi tentang jumlah oksigen yang diperlukan untuk mengoksidasi senyawa organik. COD merupakan salah satu parameter indikator pencemaran di dalam air yang di sebabkan oleh limbah organik. Keberadaannya di dalam lingkungan sangat ditentukan oleh limbah organik baik yang berasal dari limbah rumah tangga maupun industri.

Konsentrasi COD yang tinggi menyebabkan kandungan oksigen terlarut di dalam air menjadi rendah bahkan habis. Akibatnya oksigen sebagai sumber kehidupan bagi makhluk air (hewan dan tumbuh-tumbuhan) tidak dapat terpenuhi sehingga dapat mengakibatkan kematian makhluk air. Konsentrasi COD dalam air limbah di temukan berkisar 79 $700 \mathrm{mg} / \mathrm{L}$, dalam BM air limbah domestik belum mengatur kandungan COD yang diperbolehkan.

Hasil analisa air limbah menunjukkan konsentrasi detergen berada pada range 8,8$34 \mathrm{mg} / \mathrm{L}$. Pemakaian detergen dalam kegiatan rumah tangga tidak terlepas dari detergen yang digunakan untuk mencuci pakaian dan peralatan dapur. Umumnya detergen yang berada di pasaran adalah detergen yang mengandung fosfat dan sulit terurai di lingkungan. Saat ini beberapa produsen sabun telah membuat produk yang hanya mengandung sedikit zat kimia bahkan mampu menyuburkan tanah saat larut di dalam air dan bersifat ramah terhadap lingkungan karena dengan mudah dapat terurai oleh mikroorganisme.

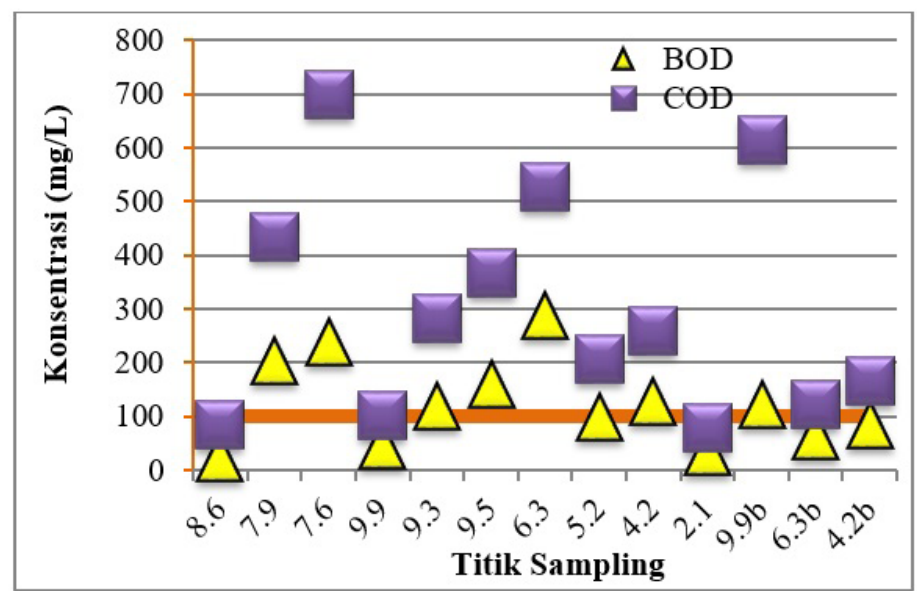

Gambar 7. Grafik BOD dan COD dalam air limbah 


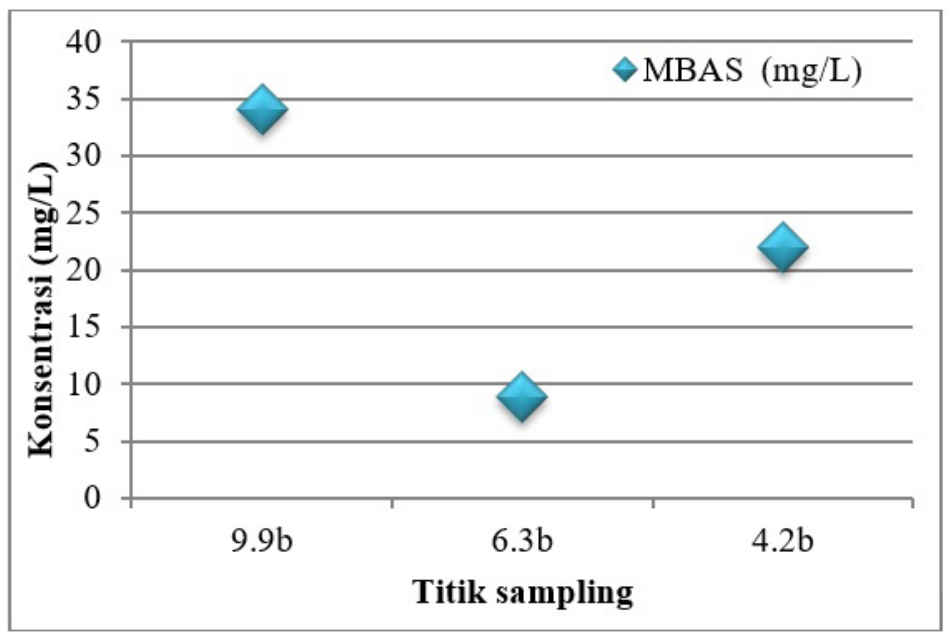

Gambar 8. Grafik MBAS dalam air limbah

Dalam BM, detergen belum di persyaratkan, namun kita akan mencoba membandingkannya dengan PP 82 tahun 2001 kriteria mutu air kelas III tentang Pengelolaan Kualitas dan Pengendalian Pencemaran Air (KMA) mensyaratkan konsentrasi detergen $200 \mu \mathrm{g} / \mathrm{L}$. Bila dibandingkan dengan kriteria mutu air yang diperbolehkan berada di perairan maka konsentrasi detergen dalam air limbah rumah tangga yang diukur dapat mencapai $40-170$ kali lebih tinggi dari yang diperbolehkan di perairan.

\section{SIMPULAN}

Hasil analisa grey water menunjukkan kisaran nilai untuk parameter $\mathrm{pH}$ 6,2 - 8,5; BOD 121 - $151 \mathrm{mg} / \mathrm{L}$; TSS 121-127 mg/L; COD 79 $700 \mathrm{mg} / \mathrm{L}$ dan minyak lemak 6 - 95 .mg/L. Hasil analisis grey water bila di bandingkan dengan peraturan Kementerian Lingkungan Hidup No 112 Tahun 2003 tentang Baku Mutu Air Limbah Domestik menunjukkan di beberapa titik $(7.9,7.6,9.3,6.3)$ mempunyai kandungan BOD, TSS dan Minyak lemak yang berada dia atas baku mutu. Parameter detergen (MBAS) konsentrasinya berkisar
$8,8-34 \mathrm{mg} / \mathrm{L}$, nilai ini 40 - 170 kali lebih tinggi dari yang diperbolehkan di badan air seperti yang diatur dalam KMA. Konsentrasi beberapa parameter dalam air limbah di buang langsung kesaluran drainase butuh pengolahan agar tidak lebih berat membebani sungai sebagai badan penerima.

\section{UCAPAN TERIMA KASIH}

Ucapan terimakasih kami sampaikan kepada ketua RW 06 Perumahan Batan Indah, Ketua RT 1- 21 pada RW 06, Kelurahan Kademangan Tangerang Selatan. Seluruh tim kuesioner dan tim sampling RPPI-12 tahun 2015 serta seluruh teman-teman di P3KLL yang terlibat baik langsung maupun tidak langsung, kegiatan ini bisa berjalan dengan baik karena peran serta kalian semua, Terimakasih.

\section{DAFTAR PUSTAKA}

(1) http://www.otakku.com/2010/06/16 /greywater-systems-menggunakankembali-air-bekas-cucian=ataumandi/\#sthash.vS7OxIN1.dpuf, di unduh tanggal 16 Agustus 2016 
(2) Cordova, M R, Kajian Air Limbah Domestik Di perumnas Bantar Kemang, Kota Bogor dan pengaruhnya pada Sungai Ciliwung.

(3) APHA, AWW, WEF, Standard Methods for the examinations of water and wastewater, 2012, 22th edition

(4) KLH, Keputusan Menteri Negara Lingkungan Hidup nomor 112 tentang bakumutu air limbah domestik, Jakarta 2003

(5) Herlambang, A, pencemaran Air dan Strategi Penanggulangannya, BPPT, JAI Vol 2, No 1 tahun 2006

(6) http://www.ubaya.ac.id/2014/content/ news_detail/1086/Teknologi-TepatGuna-Solusi-Water-Treatment-DiUTC.html, di unduh tanggal 15 Oktober 2016

(7) h t t p : / / w w w a irli mbah. com $/ 2011 / 06 / \%$ E2\%80\%9Cwarnawarni $\%$ E2\% 80\%9D-air-limbahdomestik/di unduh tanggal 16 Oktober 2016

(8) Sari, R N, Sunarto dan Wiryanto Analisis komparasi kualitas air limbah domestik berdasarkan parameter biologi dan fisika di IAL Semanggi dan IPAL Mojosongo, Jurnal Ekosains, Vol VII, No. 2, Juli 2015

(9) Hindarko, Yoshita K A, dkk, http://repository.ipb.ac.id/ handle/123456789/27859, di unduh pada 15 Oktober 2016

(10) KLHK, Rencana Strategis Lingkungan Hidup dan Kehutanan 2015-2019, Jakarta 2014
(11) KLH, Peraturan Pemerintah nomor 82 tentang Pengelolaan Kualitas dan Pengendalian Pencemaran Air, Jakarta 2001

(12) Said NI, daur ulang air limbah (water recycle) di tinjau dari aspek teknologi, lingkungan dan ekonomi, Jurnal Air Indonesia. 2012;2(2)

(13) Mulyana Y, Purmaini R, Sitorus B, Pengolahan Limbah Cair Domestik Untuk Penggunaan Ulang (Water Reuse), Journal of water Resource and Protection, 2014, (6) 1259-1267.

(14) Rochyatun E, Kaisupy MT dan Rozak A, Distribusi logam berat dalam air dan sedimen di perairan muara Cisadane, Kelompok Penelitian Pencemaran Laut, Bidang Dinamika Laut, Pusat Penelitian Oseanografi, Lembaga Ilmu Pengetahuan Indonesia,, Makara, Sains, VOL. 10, NO. 1,

(15) Aqil M, Model Pengelolaan Sumberdaya Air di Jepang, Researcher at National Research Institute for Cereals, Indonesia, Majalah inovasi ISSN 0917-8376, volume4/XVII/ agustus 2005, April 2006: 35-40

(16) Susana T, Tingkat keasaman $(\mathrm{pH})$ dan oksigen terlarut sebagai indikator kualitas perairan sekitar muara sungai Cisadane, Jurnal Teknologi Lingkungan, Vol. 5, No. 2, Desember 2009, pp. 33-39 ISSN: 1829-6572 